Check for updates

The BMJ

Cite this as: BMJ 2021;372:n807 http://dx.doi.org/10.1136/bmj.n807 Published: 23 March 2021

\title{
Covid-19: Officials query data from AstraZeneca's US vaccine trial
}

\section{Zosia Kmietowicz}

Officials from the monitoring board overseeing AstraZeneca's latest covid-19 vaccine trial have expressed concern that data released by the company this week may have been out of date and "provided an incomplete view of the efficacy data.”

AstraZeneca issued an interim analysis of its phase III trial carried out in the US, Chile, and Peru in a press release on 22 March. ${ }^{1}$ This showed that the vaccine was $79 \%$ effective at preventing symptomatic covid-19 and $100 \%$ effective at preventing severe disease and admission to hospital, though the results have yet to be formally peer reviewed.

Vaccine efficacy was consistent across all ethnic groups and in the over $65 \mathrm{~s}$, which was seen as reassuring as some European countries had failed to approve the vaccine for this age group, citing lack of data.

AstraZeneca said it would submit the data to publication in a peer reviewed journal and to the US Food and Drug Administration for emergency use authorisation.

Sarah Gilbert, professor of vaccinology at Oxford University, who led development of the vaccine there, said she couldn't see any reason why the FDA would not approve the vaccine for use in the US after scrutinising the data.

However, later that day the independent data and safety monitoring board (DSMB) overseeing the trial told federal agencies and AstraZeneca that it was concerned about the information provided in the analysis. The National Institute for Allergy and Infectious Diseases responded by urging AstraZeneca "to work with the DSMB to review the efficacy data and ensure the most accurate, up-to-date efficacy data be made public as quickly as possible."

Questions about the trial data will come as a blow to AstraZeneca, whose vaccine has been dogged by questions regarding its safety. It was recently suspended from vaccination programmes in several European countries over concerns that it increased blood clots, although most countries reinstated the vaccine after it was pronounced safe by the European Medicines Agency and WHO last week. ${ }^{2}$

The way that the trial results were released, followed by the questions from the DSMB, has been questioned by some observers.

Stephen Griffin, associate professor in the University of Leeds School of Medicine, said that it "highlights the importance of data being provided at the same time as summaries being made public.”

He added, "Naturally, the news yesterday was taken in good faith, and the issues raised by the DSMB may be a mere technicality, yet this won't be clear until we have full disclosure. Nevertheless, we must ensure that issues such as this are dealt with appropriately and that idle speculation is not seized upon by groups seeking to undermine faith in vaccination programmes."

Stephen Evans, professor of pharmacoepidemiology at the London School of Hygiene and Tropical Medicine, said that disagreements between a DSMB and investigators were not unknown but that they were usually discussed in private.

"I have said frequently that 'headline' estimates of efficacy being compared between trials is very unreliable," he said. "One explanation might well be that this trial is currently being conducted when there is a large amount of a new variant about more recently, and, as might be expected, the efficacy against that variant might be less, so more recent data shows reduced efficacy. Of course, the other vaccines may also show such reduced efficacy, and we don't know by how much.

"It does not leave me concerned particularly, unless they had found a safety issue that was being hidden, which does not appear to be the case."

In a statement AstraZeneca said, "The numbers published yesterday were based on a prespecified interim analysis with a data cut-off of 17 February.

"We have reviewed the preliminary assessment of the primary analysis and the results were consistent with the interim analysis. We are now completing the validation of the statistical analysis.

"We will immediately engage with the DSMB to share our primary analysis with the most up-to-date efficacy data. We intend to issue results of the primary analysis within 48 hours."

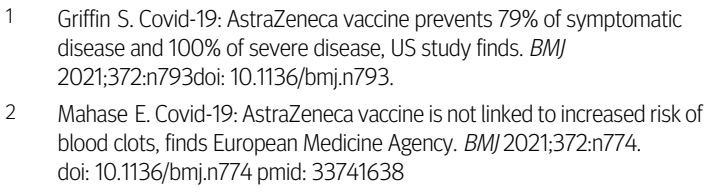

2 Mahase E. Covid-19: AstraZeneca vaccine is not linked to increased risk of blood clots, finds European Medicine Agency. BMJ 2021;372:n774. doi: 10.1136/bmj.n774 pmid: 33741638

This article is made freely available for use in accordance with BMJ's website terms and conditions for the duration of the covid-19 pandemic or until otherwise determined by BMJ. You may use, download and print the article for any lawful, non-commercial purpose (including text and data mining) provided that all copyright notices and trade marks are retained. 